\title{
Potamoplancton en la cuenca media del río Cuarto (Córdoba, Argentina)
}

\author{
Ana L. Martínez de Fabricius ${ }^{1, *}$, María E. Luque ${ }^{1}$, Daniela Lombardo ${ }^{2}$ \& E. Bruno ${ }^{1}$ \\ 1 Departamento de Ciencias Naturales \\ 2 Departamento de Microbiología, Facultad de Ciencias Exactas Físico-Químicas y Naturales. UNRC. Ruta 36 \\ Km 601 (5800) Río Cuarto, Córdoba, Argentina. mluque@exa.unrc.edu.ar.
}

* Autor responsable de la correspondencia: alujan@exa.unrc.edu.ar

\section{RESUMEN \\ Potamoplancton en la cuenca media del río Cuarto (Córdoba, Argentina)}

El objetivo de esta investigación es analizar la composición y abundancia de las algas en transporte y su relación con variables ambientales y microbiológicas en la zona de llanura aluvial ancha de la cuenca del río Cuarto. Se consideraron cinco períodos de muestreo: primavera 1999, verano 2000, otoño 2000, invierno 2000 y primavera 2000. Se seleccionaron 5 localidades en el trayecto longitudinal del río Cuarto: Tres Acequias, El Mogote (tramo urbano), Puente Antártida Argentina, Cloacas (sector de efluvios cloacales de la ciudad) y Paso del Durazno. Se recolectaron 25 muestras para el estudio biológico, 25 para el análisis microbiológico y 25 para determinar nutrientes. Las muestras de fitoplancton se obtuvieron por filtración de 100 litros de agua a través de una red de plancton de $25 \mu \mathrm{m}$ de diámetro de poro y simultáneamente se registraron parámetros fisicoquímicos e hidráulicos. Se determinaron un total de 142 taxa: 6 son Cyanophyceae, 9 son Chlorophyceae, 1 Euglenophyceae y 127 son Bacillariophyceae. La densidad algal osciló entre 215.09 células $/ \mathrm{ml}$ en Paso del Durazno, en primavera 1999 y 0.1 células $/ \mathrm{ml}$ en Tres Acequias, en otoño 2000. La máxima densidad de la clase Bacillariophyceae se registró en primavera 1999 en Paso del Durazno con 106.82 células/ml. La máxima y mínima diversidad se registró en Las Cloacas con 4.49 bits/cél en verano y 2.57 bits/cél en invierno respectivamente. La equidad varió entre 0.45 en primavera 1999 en Paso del Durazno y 0.95 en otoño para el mismo sitio de muestreo. Los resultados microbiológicos obtenidos infieren la importancia del vuelco de los efluentes cloacales al curso fluvial, evidenciado también por la presencia de especies algales de mayor valor sapróbico. Los valores del Índice Diatómico de Sladecek caracteriza al tramo en estudio dentro del rango $\beta$-mesosaprobios, contaminación moderada a alta, para los sitios Tres Acequias, El Mogote y Puente Antártica Argentina y polisaprobios, contaminación alta, en el sector Cloacas y Paso del Durazno.

Palabras clave: Algas, fitoplancton, comunidad, ríos, contaminación, diatomeas.

\begin{abstract}
Potamoplankton in the middle basin of the Cuarto River (Cordoba Argentina)

The aim of this research is to analyse the flowing algal composition and abundance as well as its relationship with the environmental and microbiological variables throughout the broad alluvial plain of the Cuarto River basin. Five sampling periods were considered: spring of 1999, summer of 2000, fall of 2000, winter 2000 and spring of 2000. Five sites were selected along the Cuarto River: Tres Acequias, El Mogote (urban stretch), Puente Antártida Argentina, Las Cloacas (city sewages outflow), and Paso del Durazno. Twenty five samples were collected for the biological study, 25 samples for microbiological analysis and 25 samples for nutrients determination. Phytoplankton samples were obtained by filtrating $100 \mathrm{~L}$ of water through a $25 \mu \mathrm{m}$ pored plankton-net, with the physicochemical and hydraulic patterns being registered at the same time. A total of 142 taxa were found: 6 Cyanophyceae, 9 Chlorophyceae, 1 Euglenophyceae and 127 Bacillariophyceae. The algal density ranged between 215.09 cells $/ \mathrm{ml}$ in the spring of 1999 at Paso del Durazno and $0.1 \mathrm{cells} / \mathrm{ml}$ in the fall of 2000 at Tres Acequias. The greatest density for the Bacillariophyceae class was registered in the spring of 1999 at Paso del Durazno with 106 cells $/ \mathrm{ml}$. The maximum and minimum diversity was registered at Las Cloacas with 4.49 bits/cell in summer and 2.57 bits/cell in winter, respectively. The equity varied between 0.45 in the spring of 1999 at Paso del Durazno and 0.95 in the fall of 2000 for the same sampling site. The microbiological results show an important effect caused by the sewage outflow, which is also indicated by the presence of algae with a high saprobic value. The Sladecek Diatomic Index values indicate that the studied river section show $\beta$-ranging mesoprobes and medium to high pollution level for Tres Acequias, El Mogote and Puente Antártida Argentina sampling sites, and polysaprobes and high pollution level for Las Cloacas and Paso del Durazno.
\end{abstract}

Keywords: Algae, phytoplankton, community, river, pollution, diatoms. 


\section{INTRODUCCIÓN}

Los ríos son componentes esenciales del paisaje continental, desde el punto de vista ecológico es totalmente diferente su funcionamiento en los distintos tramos durante su recorrido hacia su desembocadura. El río Cuarto se lo puede subdividir de los siguientes tramos: zona alta o serrana, media o llanura aluvional pedemontana y baja potámica o llanura de inundación o derrame. En el tramo medio el río se caracteriza por su capacidad autotrófica y máxima diversidad (Martínez de Fabricius, 1996). El desarrollo de las poblaciones suspendidas en el agua o potamoplancton se ve afectado por el cambio de las condiciones ambientales desde la cabecera del río hacia aguas abajo (Pérez, 2002).

Hay una combinación de factores, físicos, químicos y biológicos, que determinan la distribución de las comunidades algales (Martínez de Fabricius, et al., 2003). La importancia de cada uno de estos factores frente al resto y la magnitud con que van a afectar a las características finales del medio acuático, son los que van a determinar el tipo de ecosistema frente al que nos hallamos (Toro et al., 2002).

En Argentina, los monitoreos de ambientes acuáticos se basaron principalmente en la valoración fisicoquímica y bacteriológica del agua. Con respecto a la comunidad de algas planctónicas o en transporte, los estudios estuvieron centrados en relacionar sus cambios espaciales y temporales con las variables abióticas (Mirande et al., 1999; Tracanna et al., 1999; Luque \& Martínez de Fabricius, 2002; O'Farrell, 1993).

En la provincia de Córdoba, la mayoría de los trabajos limnológicos realizados hasta el momento, han sido llevados a cabo en la cuenca del río Tercero (Martínez de Fabricius et al., 1988; Martínez de Fabricius \& Corigliano, 1989) y cuenca del río Cuarto (Corigliano et al., 1994; Martínez de Fabricius, 1996; Luque et al., 1997; Bruno et al., 2003; Martínez de Fabricius et al., 2003). En esta última se ha determinado las características de la comunidad diatómica en relación con los factores físicos y químicos en el río Cuarto, desde su nacimiento en las Sierras de Comechingones hasta su desembocadura en los Bajos del Saladillo (Martínez de Fabricius et al., 2003).

En el marco del Proyecto que abarca el estudio y control de la calidad del agua basado en la estructura y dinámica de las comunidades algales y bacterianas en sistemas hidrográficos de la región central de la República Argentina, se considera importante analizar la estructura y distribución estacional de comunidad algal presente en el plancton en la cuenca media del curso fluvial y su relación con variables ambientales y microbiológicas durante un ciclo anual.

\section{MATERIAL Y MÉTODO}

En su recorrido, de más de $300 \mathrm{Km}$ de longitud, el río Cuarto drena una superficie de 2200 $\mathrm{km}^{2}$. Este curso fluvial nace en las Sierras de Comechingones, que junto al río Tercero integran la cuenca exorreica del Carcaraña, tributario del río Paraná, integrándose en la gran Cuenca del Plata. La cuenca media del río Cuarto discurre en la provincia geográfica Llanura Chaco-pampeana, con temperaturas medias anuales alrededor de $20^{\circ} \mathrm{C}$ en el verano, que se caracteriza por ser medianamente cálido, y con temperaturas medias mínimas de $9{ }^{\circ} \mathrm{C}$ en el invierno que es relativamente riguroso, (Seiler et al., 1995). La litología está compuesta por sedimentos del pleistoceno tardío de origen eólico y fluvial (grava y arena). En este sector de la cuenca el río presenta un patrón meándrico de variada sinuosidad y en casi toda su extensión se halla encajonado entre barrancos de hasta 12 metros de altura (Cantú \& Degiovanni, 1984).

El régimen de lluvia puede ser definido como símil-monzónico, dado que el $50 \%$ de las lluvias ocurren durante el verano y causa fuertes crecientes (Seiler et al., 1995).

Se realizó un monitoreo del plancton en distintos puntos de muestreo correspondientes a la cuenca media en la llanura aluvial del río Cuarto, durante: primavera 1999, verano 2000 , otoño 2000 , invierno 2000 y primavera 2000. En el trayecto longitudinal de este tramo del río Cuarto se seleccionaron 5 localidades, 


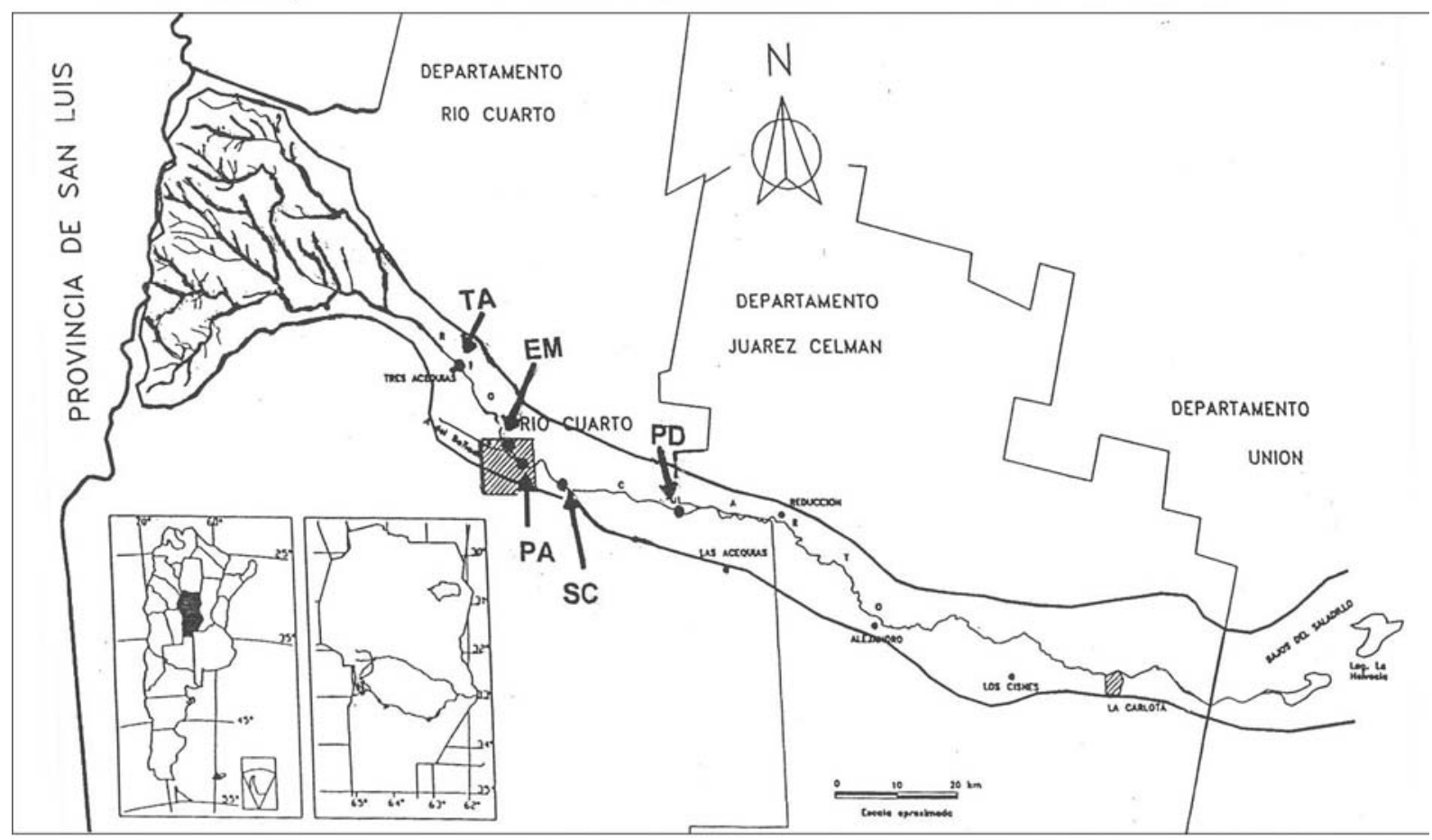

Figura 1. Mapa del río Cuarto, cuenca media, y localización de los sitios de muestreo. Map of the Cuarto River, middle basin, and locations of the sampling sites.

en puntos afectados por distinto grado de contaminación, puntual o difusa. El muestreo se realizó estacionalmente en: Tres Acequias, El Mogote (balneario-tramo urbano), Puente Antártida Argentina, Sector Cloacas (en este sector el vuelco de los efluvios cloacales urbanos aproximadamente un 50 a $60 \%$ son depurados) y Paso del Durazno, situado a $15 \mathrm{~km}$ aguas abajo del punto anterior (Fig. 1), límite sur del Departamento de Río Cuarto lindante con el Departamento de Juárez Celman hacia el sur de la provincia de Córdoba.

Se recolectaron un total de 75 muestras de las cuales 25 fueron destinadas al análisis de nutrientes y las restante al estudio biológico. Las muestras planctónicas se concentraron por filtración de 100 litros de agua a través de una red de plancton de $25 \mu \mathrm{m}$ de diámetro de poro. Las muestras se incorporaron al Herbario del Departamento de Ciencias Naturales de la UNRC, con la sigla RCC. El análisis bacteriológico fue realizado a partir de la determinación cuantitativa de bacterias mesófilas viables totales: Recuento de Aerobios Totales (RAT), a través del método de recuento en placa (UFC/ml) y de bacterias coliformes totales por el método estadístico de fermentación en múltiples tubos o número más probable (NMP/100 ml). Los resultados expresados equivalen a un número " $N " \times 10^{n}$. Los resultados originales de recuentos de bacterias coliformes totales expresados en $\mathrm{NMP} / 100 \mathrm{ml}$, fueron transformados a $1 \mathrm{ml}$, a fin de compararlos con los obtenidos del recuento de bacterias mesófilas viables totales.

En cada sitio de muestreo se registraron los siguientes parámetros fisicoquímicos e hidráulicos: temperatura y $\mathrm{pH}$ mediante el uso de $\mathrm{pH}$-metro. Altronix M-206 y la conductividad con sensor Altronix CT2, velocidad de corriente (mediante el uso de un objeto desplazado por el agua: flotador), ancho mojado y profundidad media. Las muestras de agua fueron colectadas en cada sitio y período de muestreo para su análisis químico, previamente fueron filtradas a través de filtros 
Whatman GF/C y se determinaron: Cloruros, Carbonatos, Bicarbonatos, Sulfatos, Nitritos y Nitratos, de acuerdo a procedimientos standard (APHA 1989).

Para la observación de las valvas de diatomeas las muestras fueron tratadas con agua oxigenada de 100 vol. a $80{ }^{\circ} \mathrm{C}$ durante dos horas y posteriormente lavadas con agua destilada (Battarbee, 1986). Cuando la materia orgánica no fue totalmente oxidada se aumento el tiempo de digestión. Los preparados diatomológicos permanentes se confeccionaron utilizando Naphrax $(\mathrm{R}$ como medio de montaje y fueron depositados en la colección diatomológica de la Cátedra, manteniéndose para cada uno de ellos el número de la muestra madre correspondiente.

Para el análisis taxonómico se utilizó bibliografía específica para cada grupo y/o sección en particular: Desikachary (1959), Prescott (1962), Archibald (1983), Patrick \& Reimer (1966, 1975), Germain (1981), Krammer \& LangeBertalot (1986, 1988, 1991a, 1991b), teniendo en cuenta nuevas sinonimias aceptadas (Round \& Bukhtiyarova, 1996 y Stoermer et al., 1999). Para aquellas variedades de especies que no han sido todavía sinonimizadas, en este trabajo se optó no considerar el nuevo sinónimo.

El total de las especies determinadas se ordenaron según Bourrelly $(1981,1985,1990)$ para Cyanophyceae, Chlorophyceae y Euglenophyceae y según Simonsen (1979) para las Bacillariophyceae. Con respecto a los géneros Navicula y Nitzschia se siguió el criterio nomenclatural de Krammer \& Lange-Bertalot (1986-1988).

Los recuentos se realizaron por transectos según el método propuesto por Villafañe \& Reid (1995). Se predeterminaron tres transectos horizontales equidistantes evitando los efectos de borde. Se utilizó un portaobjetos y un cubreobjetos de $24 \times 50 \mathrm{~mm}$, en el portaobjetos se sedimentó una alícuota de la muestra madre de $0.3 \mathrm{ml}$, esto permitió la observación del material con un aumento de $400 \times$. Se contaron más de un preparado hasta obtener un promedio de individuos (unicelulares, cenobios, colonias o filamentos) constante, el cual se logró con cinco preparados. Para los organismos filamentosos, Lyngbya, Oscillatoria, se consideró como unidad una lon- gitud equivalente al largo de un organismo unicelular frecuente como Synedra. Se contabilizaron pequeñas células de diatomeas que no pudieron ser determinadas a nivel taxonómico. Se expresan como: células de diatomeas no determinadas (cél. n/d).

Se confeccionaron gráficos con los valores de densidad, Indice de diversidad: $H$ (Shannon \& Weaver, 1963) y el componente de equitabilidad: $E$.

Para cada localidad estudiada se aplicó el IS = Indice de Sladecek $(1984,1986)$ que varía entre 0-4, donde: IS $=\sum s_{i} h_{i} g_{i} / \sum s_{i} h_{i}$ (s $s_{i}$ : valencia sapróbica (tolerancia a la polución orgánica: $0-4) ; g_{i}$ : valor indicador del taxón, grado de eurioicidad: $0-5 ; h_{i}$ : abundancia del taxón.

\section{RESULTADOS}

Con respecto a los registros fisicoquímicos e hidráulicos, las variaciones estacionales del $\mathrm{pH}$ no presentaron diferencias notables para cada estación y cada lugar de muestreo. Los máximos

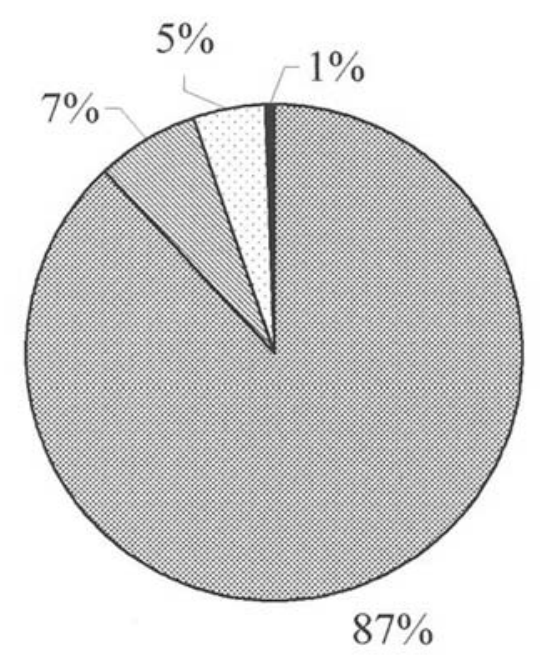

Bacillariophyceae Chlorophyceae Cyanophyceae Euglenophyceae

Figura 2. Relación porcentual anual de la densidad del fitoplancton en el río Cuarto, período primavera 1999primavera 2000. Annual percentage of the phytoplankton density in the Cuarto River, spring 1999 through spring 2000 period. 
valores de $\mathrm{pH}$ se obtuvieron principalmente en primavera de 1999 con valores cercanos o superiores a 9. La temperatura responde a las variaciones normales de las estaciones del año, con mínimos en invierno y máximos en primavera-verano, que no llegaron a superar los $25^{\circ} \mathrm{C}$. La conductividad registrada es de moderada a alta, durante todo el año y en todos los puntos de muestreo, el mayor promedio anual fue en Paso del Durazno con $363 \mu \mathrm{S} / \mathrm{cm}$. Tanto la velocidad de corriente, la profundidad y el ancho del canal fueron elevados en las épocas

Tabla 1. Características hidráulicas y fisicoquímicas de los puntos de muestreo en el río Cuarto. Hydraulical and physicochemical characteristics of the sampling points along the Cuarto River.

\begin{tabular}{|c|c|c|c|c|c|c|}
\hline \multicolumn{7}{|c|}{ a) TRES ACEQUIAS } \\
\hline & $\mathrm{Ph}$ & $\begin{array}{l}\text { Temp. } \\
{ }^{\circ} \mathrm{C}\end{array}$ & $\begin{array}{l}\text { Cond. } \\
\mu \mathrm{S} / \mathrm{cm}\end{array}$ & $\begin{array}{c}\text { Vel. Cte. } \\
\mathrm{m} / \mathrm{s}\end{array}$ & $\begin{array}{l}\text { Prof. } \\
\mathrm{cm}\end{array}$ & $\begin{array}{c}\text { Ancho } \\
\mathrm{m}\end{array}$ \\
\hline Primavera 1999 & 9.54 & 19.0 & 350.8 & 0.59 & 17.0 & 11.9 \\
\hline Verano 2000 & 8.90 & 17.0 & 352.5 & 0.98 & 24.0 & 48.3 \\
\hline Otoño 2000 & 9.64 & 10.5 & 315.0 & 0.78 & 22.0 & 85.2 \\
\hline Invierno 2000 & 8.62 & 11.5 & 370.5 & 0.75 & 30.0 & 21.3 \\
\hline Primavera 2000 & 8.57 & 15.0 & 188.7 & 0.65 & 83.0 & $\mathrm{n} / \mathrm{d}$ \\
\hline \multicolumn{7}{|c|}{ b) EL MOGOTE } \\
\hline & $\mathrm{Ph}$ & $\begin{array}{c}\text { Temp. } \\
{ }^{\circ} \mathrm{C}\end{array}$ & $\begin{array}{l}\text { Cond. } \\
\mu \mathrm{S} / \mathrm{cm}\end{array}$ & $\begin{array}{c}\text { Vel. Cte. } \\
\mathrm{m} / \mathrm{s}\end{array}$ & $\begin{array}{c}\text { Prof. } \\
\mathrm{cm}\end{array}$ & $\begin{array}{c}\text { Ancho } \\
\mathrm{m}\end{array}$ \\
\hline Primavera 1999 & 8.7 & 22.0 & 352.9 & 0.49 & 19.6 & $\overline{143.0}$ \\
\hline Verano 2000 & 8.9 & 18.4 & 274.8 & 0.79 & 21.6 & 30.0 \\
\hline Otoño 2000 & 8.8 & 11.0 & 350.0 & 0.68 & 17.0 & $\mathrm{n} / \mathrm{d}$ \\
\hline Invierno 2000 & 8.4 & 15.0 & 376.2 & 0.47 & 13.5 & 12.0 \\
\hline Primavera 2000 & 8.5 & 18.0 & 202.7 & 0.79 & 45.0 & $\mathrm{n} / \mathrm{d}$ \\
\hline \multicolumn{7}{|c|}{ c) PUENTE ANTARTIDA } \\
\hline & $\mathrm{Ph}$ & $\begin{array}{c}\text { Temp. } \\
{ }^{\circ} \mathrm{C}\end{array}$ & $\begin{array}{l}\text { Cond. } \\
\mu \mathrm{S} / \mathrm{cm}\end{array}$ & $\begin{array}{c}\text { Vel. Cte. } \\
\mathrm{m} / \mathrm{s}\end{array}$ & $\begin{array}{c}\text { Prof. } \\
\mathrm{cm}\end{array}$ & $\begin{array}{c}\text { Ancho } \\
\mathrm{m}\end{array}$ \\
\hline Primavera 1999 & 9.8 & 25.0 & 353.6 & 0.56 & 24.5 & 59.0 \\
\hline Verano 2000 & 8.9 & 22.3 & 272.0 & 0.71 & 17.6 & 28.0 \\
\hline Otoño 2000 & 8.8 & 11.0 & 348.8 & 0.65 & 22.0 & 51.2 \\
\hline Invierno 2000 & 8.6 & 16.0 & 373.7 & 0.80 & 27.3 & $\mathrm{n} / \mathrm{d}$ \\
\hline Primavera 2000 & 8.6 & 17.0 & 209.3 & 0.72 & 45.0 & $\mathrm{n} / \mathrm{d}$ \\
\hline \multicolumn{7}{|c|}{ d) SECTOR CLOACAS } \\
\hline & $\mathrm{Ph}$ & $\begin{array}{c}\text { Temp. } \\
{ }^{\circ} \mathrm{C}\end{array}$ & $\begin{array}{l}\text { Cond. } \\
\mu \mathrm{S} / \mathrm{cm}\end{array}$ & $\begin{array}{c}\text { Vel. Cte. } \\
\mathrm{m} / \mathrm{s}\end{array}$ & $\begin{array}{c}\text { Prof. } \\
\mathrm{cm}\end{array}$ & $\begin{array}{c}\text { Ancho } \\
\mathrm{m}\end{array}$ \\
\hline Primavera 1999 & 8.9 & 24.0 & 385.00 & 0.55 & 22.0 & $\overline{30.0}$ \\
\hline Verano 2000 & 8.9 & 23.4 & 266.26 & 0.76 & 38.0 & 27.3 \\
\hline Otoño 2000 & 8.8 & 11.0 & 341.40 & 0.60 & 23.0 & 66.6 \\
\hline Invierno 2000 & 8.9 & 10.0 & 402.50 & 0.52 & 38.0 & 58.0 \\
\hline Primavera 2000 & 9.1 & 17.0 & 219.35 & 0.72 & $\mathrm{n} / \mathrm{d}$ & $\mathrm{n} / \mathrm{d}$ \\
\hline \multicolumn{7}{|c|}{ e) PASO DEL DURAZNO } \\
\hline & $\mathrm{Ph}$ & $\begin{array}{c}\text { Temp. } \\
{ }^{\circ} \mathrm{C}\end{array}$ & $\begin{array}{l}\text { Cond. } \\
\mu \mathrm{S} / \mathrm{cm}\end{array}$ & $\begin{array}{c}\text { Vel. Cte. } \\
\mathrm{m} / \mathrm{s}\end{array}$ & $\begin{array}{c}\text { Prof. } \\
\mathrm{cm}\end{array}$ & $\begin{array}{c}\text { Ancho } \\
\mathrm{m}\end{array}$ \\
\hline Primavera 1999 & 8.8 & 24.0 & 443.80 & 0.44 & 21.2 & 130.0 \\
\hline Verano 2000 & 9.0 & 19.7 & 282.24 & 0.64 & 10.3 & 16.0 \\
\hline Otoño 2000 & 7.8 & 12.0 & 351.10 & 1.39 & 7.5 & 150.0 \\
\hline Invierno 2000 & 8.6 & 9.5 & 487.50 & 0.46 & 3.4 & 62.0 \\
\hline Primavera 2000 & 8.7 & 15.0 & 252.67 & 0.47 & $\mathrm{n} / \mathrm{d}$ & 62.0 \\
\hline
\end{tabular}


de lluvias. Por ejemplo la velocidad de corriente registró amplitudes entre $0.40 \mathrm{~m} / \mathrm{s}$ y $1 \mathrm{~m} / \mathrm{s}$ en épocas de estiaje (Tabla 1).

El agua del río Cuarto ha sido descripta como "bicarbonatadas". En el tramo estudiado, la conductividad, los sólidos sedimentables (S.D.T) y los aniones disueltos se incre- mentaron progresivamente río abajo, principalmente los nitritos y nitratos en la zona de Cloacas y Paso del Durazno (Tabla 2).

Se determinaron un total de 142 taxones en la comunidad fitoplanctónica del río Cuarto. De ellos, 6 Cyanophyceae, 9 Chlorophyceae, $1 \mathrm{Eu}$ glenophyceae y 127 Bacillariophyceae (Tabla 3).

Tabla 2. Valores de sólidos sedimentables, aniones y cationes disueltos obtenidos en los sitios de estudio en el río Cuarto. Las abreviaciones son las siguientes: TDS: sólidos disueltos o en suspensión totales; ${ }^{-} \mathrm{HCO}_{3}$ : bicarbonatos; $\mathrm{SO}_{4}^{=}$; sulfatos: $\mathrm{Cl}^{-}$: cloruros; ${ }^{-} \mathrm{NO}_{3}$ : nitratos; ${ }^{-} \mathrm{NO}_{2}$ : nitritos. Values of sedimentary solids, and dissolved anions and cations obtained in the studied sites along the Cuarto River. The abbreviations are: TDS: total dissolved or in suspension solids; ${ }^{-} \mathrm{HCO}_{3}$ : bicarbonates; $\mathrm{SO}_{4}^{=}$; sulphates: $\mathrm{Cl}^{-}$: chlorides; ${ }^{-} \mathrm{NO}_{3}$ : nitrates; ${ }^{-} \mathrm{NO}_{2}$ : nitrites.

\begin{tabular}{|c|c|c|c|c|c|c|c|c|c|c|}
\hline \multicolumn{11}{|c|}{ a) Primavera de 1999} \\
\hline S.D.T & $\mathrm{CO}_{3} \mathrm{H}^{=}$ & $\mathrm{SO}_{4}^{=}$ & $\mathrm{Cl}^{-}$ & $\mathrm{Na}^{+}$ & $\mathrm{K}$ & $\mathrm{Ca}$ & $\mathrm{Mg}$ & $\mathrm{F}$ & $\mathrm{NO}_{3}$ & $\mathrm{NO}_{2}$ \\
\hline $\mathrm{mg} / \mathrm{l}$ & $\mathrm{mg} / \mathrm{l}$ & $\mathrm{mg} / \mathrm{l}$ & $\mathrm{mg} / \mathrm{l}$ & $\mathrm{mg} / \mathrm{l}$ & $\mathrm{mg} / \mathrm{l}$ & $\mathrm{mg} / \mathrm{l}$ & $\mathrm{mg} / \mathrm{l}$ & $\mathrm{mg} / \mathrm{l}$ & $\mathrm{mg} / \mathrm{l}$ & $\mathrm{mg} / \mathrm{l}$ \\
\hline 197.00 & 115.0 & 32.6 & 11.4 & 14.2 & 2.9 & 26.4 & 6.8 & 0.39 & 5.00 & 0.00 \\
\hline 209.00 & 115.0 & 34.2 & 11.4 & 14.2 & 3.4 & 30.4 & 7.3 & 0.34 & 5.00 & 0.00 \\
\hline 229.00 & 157.5 & 12.2 & 14.3 & 15.2 & 3.8 & 32.8 & 6.8 & 0.42 & 5.00 & 0.00 \\
\hline 224.00 & 135.0 & 37.0 & 14.3 & 15.2 & 3.7 & 33.6 & 8.3 & 0.37 & 8.00 & 0.00 \\
\hline 279.00 & 160.0 & 42.1 & 20.0 & 23.3 & 4.6 & 36.8 & 7.8 & 0.37 & 5.00 & 0.05 \\
\hline
\end{tabular}

b) Verano de 2000

\begin{tabular}{ccccccccccc}
\hline $\begin{array}{c}\text { S.D.T } \\
\mathrm{mg} / \mathrm{l}\end{array}$ & $\begin{array}{c}\mathrm{CO}_{3} \mathrm{H}^{-} \\
\mathrm{mg} / \mathrm{l}\end{array}$ & $\begin{array}{c}\mathrm{SO}_{4}^{=} \\
\mathrm{mg} / \mathrm{l}\end{array}$ & $\begin{array}{c}\mathrm{Cl}^{-} \\
\mathrm{mg} / \mathrm{l}\end{array}$ & $\begin{array}{c}\mathrm{Na}^{+} \\
\mathrm{mg} / \mathrm{l}\end{array}$ & $\begin{array}{c}\mathrm{K} \\
\mathrm{mg} / \mathrm{l}\end{array}$ & $\begin{array}{c}\mathrm{Ca} \\
\mathrm{mg} / \mathrm{l}\end{array}$ & $\begin{array}{c}\mathrm{Mg} \\
\mathrm{mg} / \mathrm{l}\end{array}$ & $\begin{array}{c}\mathrm{F}^{2} \\
\mathrm{mg} / \mathrm{l}\end{array}$ & $\begin{array}{c}\mathrm{NO}_{3} \\
\mathrm{mg} / \mathrm{l}\end{array}$ & $\begin{array}{c}\mathrm{NO}_{2} \\
\mathrm{mg} / \mathrm{l}\end{array}$ \\
\hline 165.00 & 94.1 & 18.1 & 8.6 & 7.1 & 2.5 & 19.2 & 5.4 & 0.23 & 2.27 \\
172.00 & 113.9 & 16.9 & 10.0 & 9.1 & 2.8 & 24.8 & 4.9 & 0.24 & 2.13 & 0.03 \\
174.00 & 118.8 & 18.5 & 12.9 & 11.1 & 3.0 & 24.0 & 6.8 & 0.27 & 3.04 & 0.03 \\
178.00 & 118.8 & 16.9 & 14.3 & 10.1 & 3.3 & 24.0 & 6.8 & 0.27 & 4.43 & 0.2 \\
202.00 & 138.6 & 16.9 & 14.3 & 13.1 & 3.6 & 30.4 & 5.4 & 0.27 & 4.86 & 0.02
\end{tabular}

\begin{tabular}{|c|c|c|c|c|c|c|c|c|c|c|}
\hline \multicolumn{11}{|c|}{ c) Otoño de 2000} \\
\hline $\begin{array}{l}\text { S.D.T } \\
\mathrm{mg} / \mathrm{l}\end{array}$ & $\begin{array}{c}\mathrm{CO}_{3} \mathrm{H}^{=} \\
\mathrm{mg} / \mathrm{l}\end{array}$ & $\begin{array}{l}\mathrm{SO}_{4}^{=} \\
\mathrm{mg} / \mathrm{l}\end{array}$ & $\begin{array}{c}\mathrm{Cl}^{-} \\
\mathrm{mg} / \mathrm{l}\end{array}$ & $\begin{array}{l}\mathrm{Na}^{+} \\
\mathrm{mg} / \mathrm{l}\end{array}$ & $\begin{array}{c}\mathrm{K} \\
\mathrm{mg} / \mathrm{l}\end{array}$ & $\begin{array}{c}\mathrm{Ca} \\
\mathrm{mg} / \mathrm{l}\end{array}$ & $\begin{array}{l}\mathrm{Mg} \\
\mathrm{mg} / \mathrm{l}\end{array}$ & $\begin{array}{c}\mathrm{F} \\
\mathrm{mg} / \mathrm{l}\end{array}$ & $\begin{array}{l}\mathrm{NO}_{3} \\
\mathrm{mg} / \mathrm{l}\end{array}$ & $\begin{array}{l}\mathrm{NO}_{2} \\
\mathrm{mg} / \mathrm{l}\end{array}$ \\
\hline 152.00 & 115.0 & 21.2 & 11.4 & 10.1 & 2.2 & 23.2 & 5.9 & 0.44 & 0.00 & 0.00 \\
\hline 90.00 & 57.5 & 38.5 & 11.4 & 9.1 & 2.3 & 12.00 & 7.3 & 0.55 & 2.00 & 0.00 \\
\hline 167.00 & 122.5 & 22.0 & 14.3 & 11.6 & 2.5 & 26.4 & 5.9 & 0.44 & 5.00 & 0.00 \\
\hline 172.00 & 126.3 & 11.4 & 14.3 & 11.6 & 2.5 & 25.6 & 7.3 & 0.55 & 10.0 & 0.00 \\
\hline 170.00 & 122.5 & 17.3 & 14.3 & 12.1 & 2.8 & 24.8 & 5.9 & 0.44 & 5.00 & 0.00 \\
\hline
\end{tabular}

\begin{tabular}{|c|c|c|c|c|c|c|c|c|c|c|}
\hline \multicolumn{11}{|c|}{ d) Invierno de 2000} \\
\hline $\begin{array}{c}\text { S.D.T } \\
\mathrm{mg} / \mathrm{l}\end{array}$ & $\begin{array}{c}\mathrm{CO}_{3} \mathrm{H}^{=} \\
\mathrm{mg} / \mathrm{l}\end{array}$ & $\begin{array}{l}\mathrm{SO}_{4}^{=} \\
\mathrm{mg} / 1\end{array}$ & $\begin{array}{c}\mathrm{Cl}^{-} \\
\mathrm{mg} / \mathrm{l}\end{array}$ & $\begin{array}{l}\mathrm{Na}^{+} \\
\mathrm{mg} / \mathrm{l}\end{array}$ & $\begin{array}{c}\mathrm{K} \\
\mathrm{mg} / \mathrm{l}\end{array}$ & $\begin{array}{c}\mathrm{Ca} \\
\mathrm{mg} / \mathrm{l}\end{array}$ & $\begin{array}{c}\mathrm{Mg} \\
\mathrm{mg} / \mathrm{l}\end{array}$ & $\begin{array}{c}\mathrm{F} \\
\mathrm{mg} / \mathrm{l}\end{array}$ & $\begin{array}{l}\mathrm{NO}_{3} \\
\mathrm{mg} / \mathrm{l}\end{array}$ & $\begin{array}{l}\mathrm{NO}_{2} \\
\mathrm{mg} / \mathrm{l}\end{array}$ \\
\hline 190.00 & 82.5 & 40.1 & 20.0 & 8.1 & 0.1 & 25.6 & 8.3 & 0.35 & 0.00 & 0.00 \\
\hline 200.00 & 120.0 & 29.5 & 11.4 & 12.1 & 3.0 & 28.8 & 6.3 & 0.42 & 3.43 & 0.03 \\
\hline 203.00 & 125.0 & 25.6 & 12.9 & 14.2 & 3.0 & 29.6 & 6.3 & 0.42 & 4.77 & 0.00 \\
\hline 211.00 & 145.0 & 22.8 & 10.0 & 13.1 & 3.2 & 31.2 & 6.8 & 0.40 & 5.16 & 0.03 \\
\hline 237.00 & 162.5 & 24.0 & 11.4 & 17.2 & 3.4 & 34.4 & 8.8 & 0.44 & 5.77 & 0.00 \\
\hline
\end{tabular}




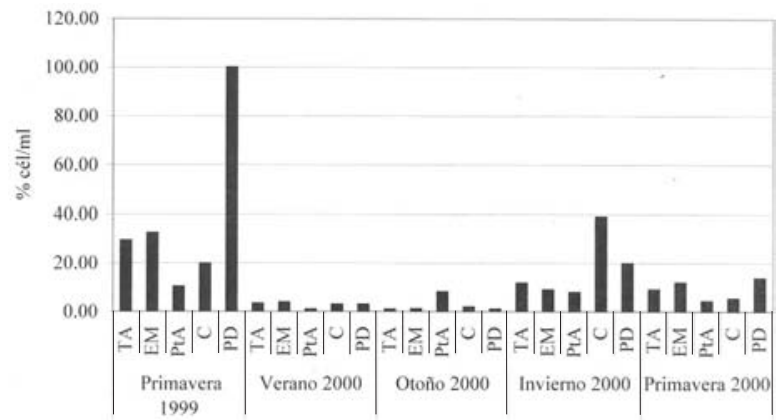

Figura 3. Porcentaje de densidad (cél/ml) de las algas en transporte en el río Cuarto, para cada estación del año. A: primavera'99, B: verano'00, C: otoño'00, D: invierno'00, E: primavera'00. Density (cells/ml) percentage of flowing algae in the Cuarto River, for each season. A: spring of 1999; B: summer of 2000; C: fall of 2000; D: winter of 2000 and E: spring of 2000 .

La clase Bacillariophyceae registró mayor abundancia y representó un $87 \%$ de la densidad fitoplanctónica, mientras que las Chlorophyceae aportaron un $7 \%$, las Cyanophyceae $5 \%$ y las Euglenophyceae un $1 \%$ (Fig. 2).

La densidad osciló entre 215.09 células $/ \mathrm{ml}$ en Paso del Durazno, en primavera 1999 y 0.1 células/ml en Tres Acequias, en otoño 2000 (Fig. 3).

Las Bacillariophyceae fueron las que aportaron la mayor densidad en todos los sitios de muestreo y a lo largo del período de estudio. En el Paso del Durazno las diatomeas fueron más abundantes con 106.82 células/ml. Las Chlorophyceae registraron su máxima densidad en el Mogote durante el otoño y tanto las Cyanophyceae como Euglenophyceae registraron valores muy bajos de abundancia en todos los sitios de muestreo (Fig. 4).

En el gradiente longitudinal del río prevalecieron las especies de diatomeas, en número de especies y en porcentaje de densidad con variaciones para cada sitio de muestreo y época del año. En primavera de 1999, las especies con mayor porcentaje fueron: Achnanthidium minutissimum (24\%) y Nitzschia linearis (26\%) en El Mogote, Nitzschia linearis (31\%) y $\mathrm{Na}$ vicula perminuta $(24 \%)$ en Puente Antártida Argentina. Ésta última especie también registró valores elevados en las Cloacas (27 \%) y Nitzschia palea (55\%) en Paso de Durazno (Tabla 4 y Fig. 5). En el verano de 2000,
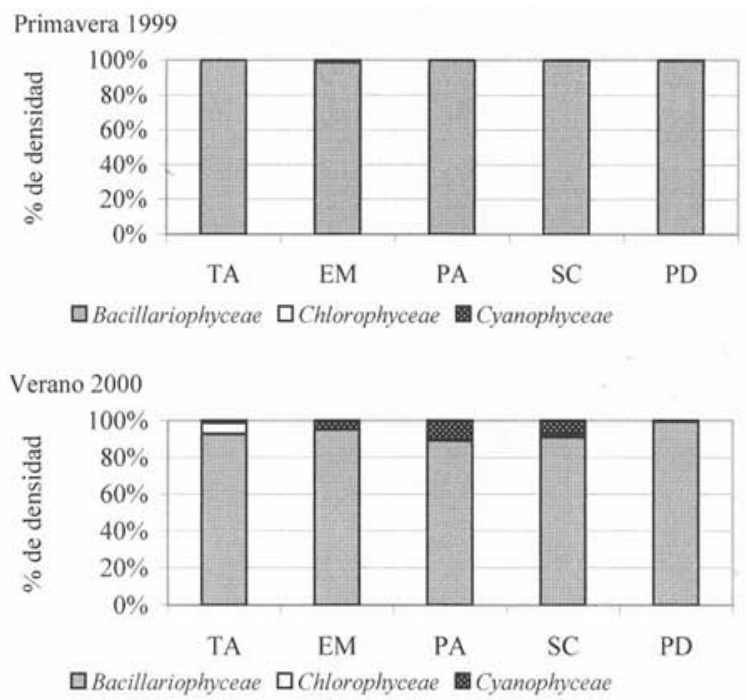

Otoño

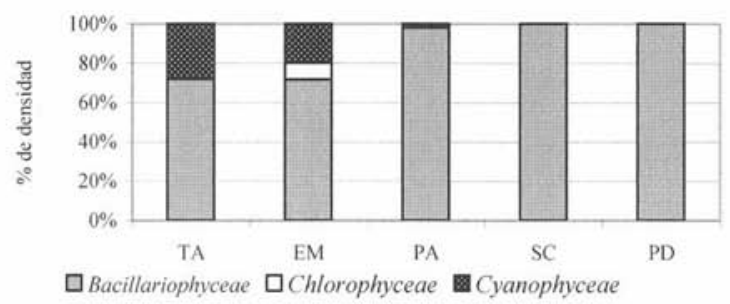

Invierno
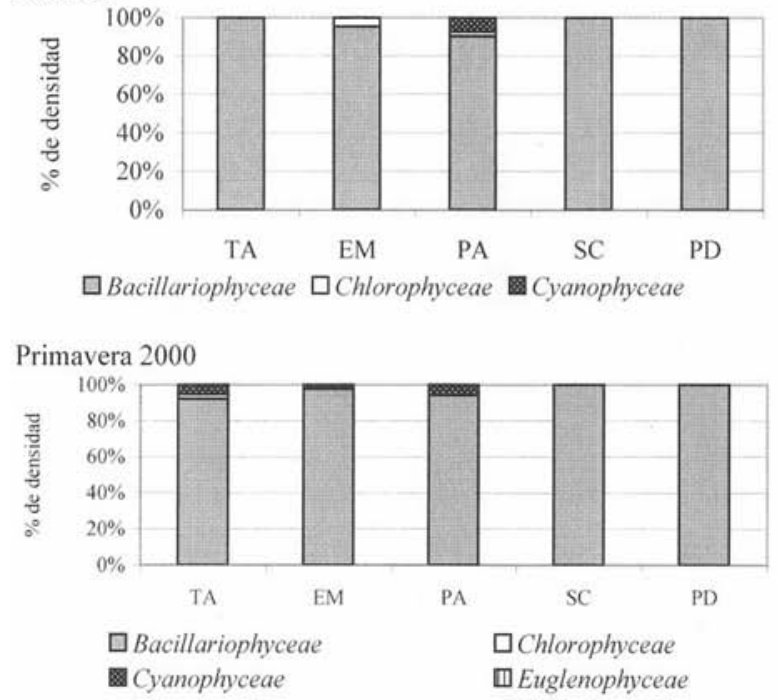

Figura 4. Distribución estacional del porcentaje de densidad por clase algal, registrado en el río Cuarto, período primavera 1999-primavera 2000. Seasonal distribution of density percentage for each algae class, registered in the Cuarto River, spring 1999 trough spring 2000 period. 
Tabla 3. Composición taxonómica de las algas en transporte en los puntos de muestreo del río Cuarto, durante un ciclo anual, primavera'99-primavera'00. Taxonomic composition of flowing algae at the sampling points along the Cuarto River, during the annual cycle from the spring of 1999 to the spring of 2000.

\begin{tabular}{|c|c|}
\hline Clase CYANOPHYCEAE & Fragilaria sp. \\
\hline Orden: Chroococcales & Fragilaria vaucheriae (Kützing) J. B. Peterson \\
\hline Chroococcus sp. & Fragilaria virescens Ralfs \\
\hline Merismopedia sp. & Frustulia vulgaris (Twhaites) De Toni \\
\hline Orden: Nostocales & Geissleria decussis (Oestrus) Lange-Bertalot \& Metzeltin \\
\hline Anabaena sp. & Gomphonema olivaceum (Lyngbye) Kützing \\
\hline Orden: Oscillatoriales & Gomphonema parvulum (Kützing) Grunow \\
\hline Lyngbya sp. & Gomphonema truncatum Ehrenberg \\
\hline Oscillatoria tenuis Agardh & Gyrosigma acuminatum (Kützing) Rabenhorst \\
\hline Oscillatoria sp. & Hantzschia amphioxys (Ehrenberg) Grunow \\
\hline Clase: CHLOROPHYCEAE & Navicula capitata Ehrenberg \\
\hline Orden: Volvocales & Navicula capitata var. hungarica (Grunow) Ross \\
\hline Chlamydomonas sp. & Navicula cryptocephala Kützing \\
\hline Orden: Chlorococcales & Navicula cryptocephala var. veneta (Kützing) Rabenhorst \\
\hline Ankistrodesmus falcatus (Corda) Ralfs & Navicula exigua Gregory ex Grunow \\
\hline Monoraphidium sp. & Navicula exilis Kützing \\
\hline Oocystis sp. & Navicula menisculus var. upsaliensis (Grunow) Grunow \\
\hline Scenedesmus acuminatus (Lagerheim) Chodat & Navicula perminuta (Grunow) Peragallo \\
\hline Scenedesmus acutus Meyen & Navicula pseudoreinhardtii Patrick \\
\hline Scenedesmus quadricauda (Turp.) Brébisson & Navicula radiosa Kützing \\
\hline Scenedesmus spinosus Chodat & Navicula radiosa var. parva Wallace \\
\hline Orden: Cylindrocapsales & Navicula radiosa var. tenella (Brébisson) Grunow \\
\hline Cylindrocapsa sp. & Navicula rhyncocephala Kützing \\
\hline Clase: EUGLENOPHYCEAE & Navicula salinarum Grunow \\
\hline Orden: Euglenales & Navicula tripunctata (O. F. Müller) Bory \\
\hline Euglena sp. & Navicula veneta Kützing \\
\hline Clase: BACILLARIOPHYCEAE & Navicula viridula (Kützing) Ehrenberg \\
\hline Orden: Centrales & Navicula viridula var. linearis Hustedt \\
\hline Aulacoseira granulata (Ehrenberg) Simonsen & Nitzschia acicularis (Kützing) W Smith \\
\hline Aulacoseira italica (Ehrenberg) Simonsen & Nitzschia amphibia Grunow \\
\hline Aulacoserira sp. & Nitzschia bacillum Hustedt \\
\hline Cyclotella meneghiniana Kützing Melosira varians Agardh & Nitzschia capitellata Hustedt \\
\hline Orden: Pennales & Nitzschia clausii Hantzsch \\
\hline Achnanthes biasoletiana (Kützing) Grunow & Nitzschia constricta (Gregory) Grunow \\
\hline Achnanthes coarctata (Brébisson) Grunow & Nitzschia dissipata (Kützing) Grunow \\
\hline Achnanthes inflata (Kützing) Grunow & Nitzschia fonticola Grunow \\
\hline Achnanthes lanceolata var. dubia Grunow & Nitzschia frustulum (Kützing) Grunow \\
\hline Achnanthes lanceolata var. frecuentissima Lange-Bertalot & Nitzschia frustulum var. bulnheimiana (Rabenhorst) Grunow \\
\hline Achnanthes lanceolata var. omissa $\mathrm{C}$. W. Reimer & Nitzschia gandersheimiensis Krasske \\
\hline Achnanthes microcephala (Kützing) Grunow & Nitzschia hantzschiana Rabenhorst \\
\hline Achnanthes sp. & Nitzschia inconspicua Grunow \\
\hline Achnanthidium minutissimum (Kützing) Czarnecki & Nitzschia lacuum Lange-Bertalot \\
\hline Achnanthidium exiguum (Grunow) Czarnecki & Nitzschia linearis (Agardh) Smith \\
\hline Amphipleura lindehimeri Grunow & Nitzschia microcephala Grunow \\
\hline Amphora pediculus (Kützing) Grunow & Nitzschia palea (Kützing) W. Smith \\
\hline Amphora sabiniana Reimer & Nitzschia perminuta (Grunow) M. Peragallo \\
\hline
\end{tabular}


Tabla 3. (Cont.)

\begin{tabular}{|c|c|}
\hline Caloneis bacillum (Grunow) Cleve & Nitzschia pusilla Grunow \\
\hline Cocconeis fluviatilis J. H. Wallace & Nitzschia recta Hantzsch \\
\hline Cocconeis placentula var. euglypta (Ehrenberg) Grunow & Nitzschia sigma (Kützing) W. Smith \\
\hline Cocconeis placentula var. lineata (Ehrenberg) Van Heurck & Nitzschia sigmoidea (Nitzsch) W. Smith \\
\hline Craticula cuspidata (Kützing) D. G. Mann & Nitzschia sp. \\
\hline Cymatopleura solea (Brébisson \& Godey) W. Smith & Nitzschia umbonata (Ehrenberg) Lange-Bertalot \\
\hline Cymbella affinis Kützing & Pinnularia borealis Ehrenberg \\
\hline Cymbella cymbiformis Agardh & Pinnularia borealis var. rectangularis Carlson \\
\hline Cymbella silesiaca Bleisch & Pinnularia brebisonii (Kützing) Rabhenharts \\
\hline Cymbella tumida (Brébisson) Van Heurck & Pinnularia divergens var. paralella (Brunow) Pratrick \\
\hline Denticula kuetzingii Grunow & Pinnularia latevittata var. dominguensis Cleve \\
\hline Denticula sp. & Pinnularia mesogongyla Ehrenberg \\
\hline Diatoma anceps (Ehrenberg) Kirchner & Pinnularia nobilis (Ehrenberg) Ehrenberg \\
\hline Diatoma tenue Agardh & Pinnularia viridis (Nitzsch) Ehrenberg \\
\hline Diatoma vulgare Bory & Planothidium lanceolatum (Brébisson) Round \& Bukhtiyarova \\
\hline Diatoma vulgare var. breve Grunow & Reimeria uniseriata Sala et al. \\
\hline Diatoma vulgare var. linearis Van Heurck & Rhopalodia gibba (Ehrenberg) Müller \\
\hline Diploneis ovalis (Hilse) Cleve & Rhopalodia gibba var. ventricosa (Kützing) H. et M. Peragallo \\
\hline Diploneis puella (Schum.) Cleve & Rhopalodia musculus (Kützing) O Müller \\
\hline Encyonema minutum (Hilse \& ex Rabenhorst) D. G. Mann & Rhoicosphenia abbreviatta (Agardh) Lange-Bertalot \\
\hline Epithemia adnata (Kützing) Brébisson & Rhoicosphenia curvata (Kützing) Grunow \\
\hline Epithemia sorex Kützing & Rossithidium linearis (W. Smith) Round \& Bukhtiyarova \\
\hline Epithemia sp. & Sellaphora pupula (Kützing) Mereschkowksy \\
\hline Eunotia sp. & Stauroneis anceps Ehrenberg \\
\hline Fragilaria brevistriata Grunow & Surirella angusta Kützing \\
\hline Fragilaria capucina Desmaziéres & Surirella linearis W. Smith \\
\hline Fragilaria capucina var. gracilis (Oestrup) Hustedt & Surirella ovalis Brébisson \\
\hline Fragilaria capucina var. mesolepta Rabenhorst & Synedra acus Kützing \\
\hline Fragilaria fasciculata (Agardh) Lange-Bertalot & Synedra ulna (Nitzsch) Ehrenberg \\
\hline
\end{tabular}

Tabla 4. Composición específica y porcentaje de densidad (cél/ml) de las algas en el río Cuarto, período primavera 1999-primavera 2000. Del total de especies se seleccionaron aquellas con mayor densidad durante el ciclo anual. Specific composition and density percentage (cell/ml) of algae in the Cuarto River, during the spring 1999 through spring 2000 period. From the total species, those with greatest density were selected during the annual cycle.

\begin{tabular}{|c|c|c|c|c|c|c|c|c|c|c|c|c|c|c|c|c|c|c|c|c|c|c|c|c|c|}
\hline \multirow[b]{2}{*}{ Especies } & \multicolumn{5}{|c|}{ PRIMAVERA 1999} & \multicolumn{5}{|c|}{ VERANO 2000} & \multicolumn{5}{|c|}{ OTOÑO 2000} & \multicolumn{5}{|c|}{ INVIERNO 2000} & \multicolumn{5}{|c|}{ PRIMAVERA 2000} \\
\hline & $\mathrm{TA}$ & EM & $\mathrm{PA}$ & SC & PD & $\mathrm{TA}$ & EM & $\mathrm{PA}$ & $\mathrm{SC}$ & PD & $\mathrm{TA}$ & EM & $\mathrm{PA}$ & SC & PD & TA & EM & PA & $\mathrm{SC}$ & PD & TA & EM & PtA & $\mathrm{C}$ & PD \\
\hline \multicolumn{26}{|l|}{ BACILLARIOPHYCEAE } \\
\hline Achnanthidium minutissimum & 12.35 & 23.58 & 1.66 & 1.17 & 0.03 & 4.50 & 2.92 & 0.00 & 4.12 & 0.00 & 6.95 & 5.83 & 1.50 & 1.32 & 7.33 & 8.14 & 1.24 & 0.00 & 1.34 & 2.08 & 2.81 & 1.47 & 3.60 & 4.27 & 12.66 \\
\hline Amphora pediculus & 15.42 & 3.71 & 1.26 & 5.93 & 0.29 & 0.56 & 0.48 & 0.00 & 0.00 & 0.00 & 10.42 & 0.00 & 1.60 & 0.00 & 7.34 & 2.69 & 1.24 & 0.00 & 0.10 & 0.29 & 0.85 & 0.00 & 0.00 & 0.00 & 1.58 \\
\hline Células de diatomeas $n / d$ & 2.43 & 4.12 & 8.88 & 5.95 & 3.48 & 11.16 & 4.82 & 22.31 & 9.70 & 9.07 & 0.00 & 10.83 & 3.92 & 10.68 & 19.50 & 2.71 & 1.24 & 4.38 & 2.17 & 6.99 & 3.30 & 8.31 & 7.07 & 20.17 & 4.75 \\
\hline $\begin{array}{l}\text { Cocconeis placentula } \\
\text { var. euglypta }\end{array}$ & 1.95 & 7.58 & 1.66 & 1.87 & 0.07 & 2.54 & 3.94 & 2.48 & 3.15 & 1.01 & 0.00 & 0.00 & 2.81 & 13.37 & 14.66 & 0.00 & 0.53 & 0.00 & 0.41 & 0.45 & 1.59 & 0.00 & 1.73 & 1.83 & 0.79 \\
\hline $\begin{array}{l}\text { Cocconeis placentula } \\
\text { var. lineata }\end{array}$ & 10.04 & 0.00 & 2.94 & 4.91 & 0.17 & 4.50 & 2.92 & 0.00 & 4.85 & 5.71 & 10.52 & 0.00 & 1.96 & 5.34 & 0.00 & 0.95 & 0.00 & 1.01 & 0.62 & 0.45 & 0.00 & 0.61 & 3.07 & 3.67 & 1.26 \\
\hline Diatoma vulgare & 0.39 & 0.25 & 0.39 & 0.43 & 0.03 & 0.59 & 0.00 & 0.00 & 0.73 & 0.00 & 0.00 & 5.83 & 0.20 & 1.32 & 12.17 & 13.17 & 8.33 & 19.20 & 31.16 & 15.63 & 24.43 & 32.39 & 27.08 & 27.50 & 36.24 \\
\hline Synedra ulna & 2.04 & 5.13 & 4.83 & 3.78 & 1.17 & 11.75 & 0.00 & 8.26 & 5.58 & 5.71 & 6.95 & 10.83 & 5.02 & 0.00 & 12.17 & 3.66 & 6.56 & 13.47 & 3.66 & 8.48 & 4.52 & 3.20 & 5.74 & 6.71 & 3.16 \\
\hline Melosira varians & 0.36 & 2.53 & 2.22 & 1.48 & 0.00 & 0.00 & 0.00 & 0.00 & 4.12 & 0.00 & 0.00 & 0.00 & 1.76 & 6.66 & 0.00 & 0.00 & 8.33 & 19.20 & 36.57 & 22.17 & 4.52 & 0.26 & 3.60 & 0.00 & 2.21 \\
\hline Navicula perminuta & 27.80 & 0.00 & 24.25 & 26.49 & 0.00 & 9.79 & 0.00 & 14.05 & 5.58 & 3.36 & 14.00 & 14.16 & 33.48 & 0.00 & 0.00 & 9.91 & 14.72 & 3.37 & 0.00 & 0.00 & 8.18 & 14.20 & 12.00 & 0.00 & 0.00 \\
\hline Navicula rhyncocephala & 0.08 & 0.76 & 1.66 & 1.74 & 0.36 & 0.59 & 27.08 & 0.00 & 0.73 & 0.00 & 0.00 & 0.00 & 0.85 & 0.00 & 0.00 & 0.00 & 0.53 & 1.01 & 0.00 & 0.00 & 0.85 & 0.61 & 0.40 & 0.00 & 0.00 \\
\hline Nitzschia frustulum & 1.95 & 1.26 & 0.94 & 1.00 & 0.10 & 1.96 & 0.00 & 0.00 & 0.00 & 0.00 & 3.16 & 0.00 & 0.65 & 1.32 & 4.84 & 1.76 & 0.53 & 0.00 & 8.51 & 8.93 & 0.37 & 0.00 & 0.93 & 4.88 & 12.82 \\
\hline Nitzschia linearis & 6.89 & 25.78 & 30.91 & 19.85 & 9.14 & 4.50 & 0.00 & 10.74 & 4.12 & 2.35 & 0.00 & 0.00 & 28.28 & 9.35 & 7.33 & 7.19 & 21.81 & 0.00 & 9.29 & 22.77 & 9.40 & 6.32 & 9.74 & 6.71 & 5.54 \\
\hline Nitzschia palea & 1.48 & 4.46 & 4.83 & 8.38 & 54.78 & 5.29 & 4.82 & 2.48 & 10.43 & 11.09 & 0.00 & 0.00 & 2.81 & 0.00 & 0.00 & 8.14 & 7.63 & 9.09 & 0.05 & 0.00 & 4.89 & 5.80 & 3.07 & 0.00 & 0.00 \\
\hline
\end{tabular}



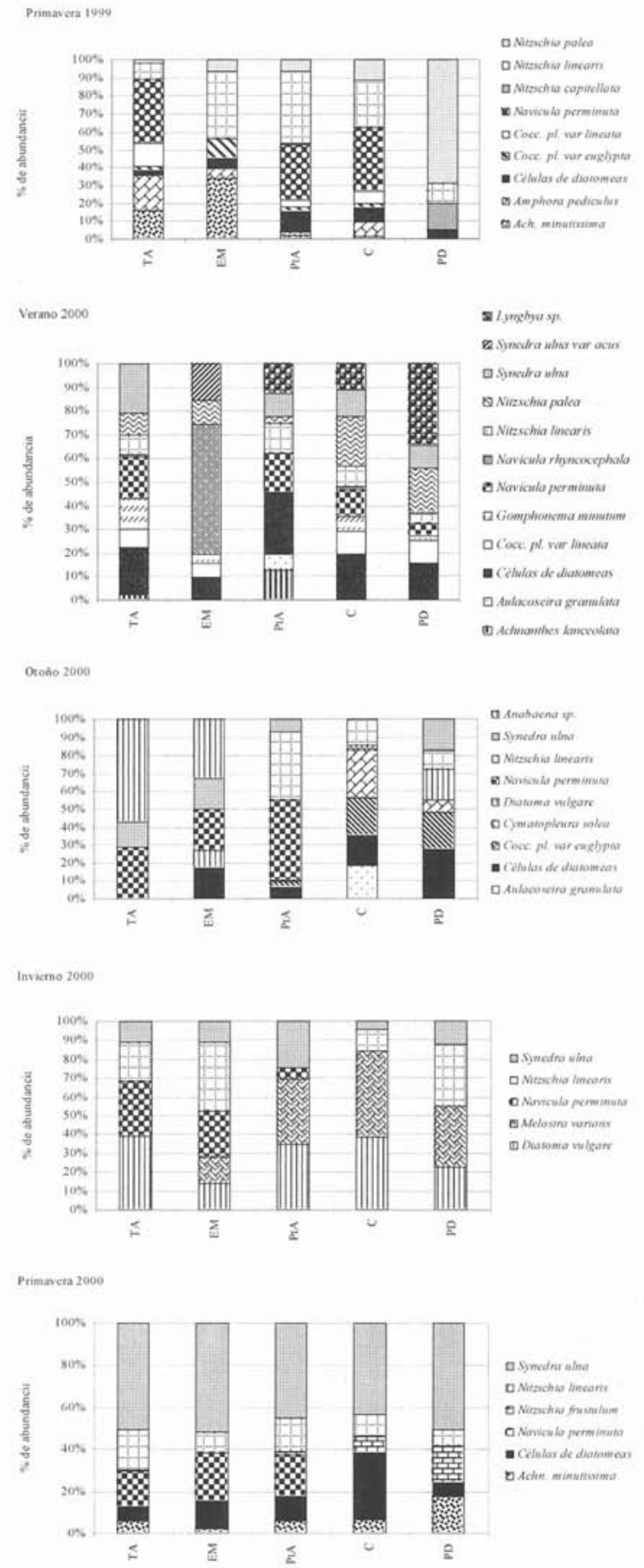

Figura 5. Participación porcentual de las especies fitoplanctónicas, con más del $5 \%$ de abundancia, en los sitios de muestreos del río Cuarto para cada estación del año. Percentage contribution of the phytoplankton species showing more than $5 \%$ of abundance at the sampling sites along the Cuarto River for each year season.
Navicula rhyncocephala en El Mogote y células de diatomeas n/d en Puente Antártida Argentina registraron densidades de $27 \%$ y $22 \%$ respectivamente. En Paso del Durazno Lynbya sp. fue la Cyanophyceae más abundante (20\%) (Tabla 4 y Fig. 5).

En otoño las especies Navicula perminuta y Nitzschia linearis registraron los porcentajes elevados, en Puente Antártida Argentina con $35 \%$ y $28 \%$ respectivamente. Anabaena sp. fue abundante en Tres Acequias y El Mogote con porcentajes de $28 \%$ y $20 \%$ respectivamente (Tabla 4 y Fig. 5). En invierno fueron abundantes en las Cloacas, Diatoma vulgare $(31 \%)$ y Melosira varians (37 \%), mientras que Nitzschia linearis registró porcentajes muy similares en El Mogote $(22 \%)$ y en Paso del Durazno (23\%) (Tabla 4 y Fig. 5). En la primavera 2000 en todos los lugares estudiados hubo un notorio predominio de Synedra ulna con respecto al resto de las especies (Tabla 4 y Fig. 5).

En el sector de las Cloacas se registraron la máxima y la mínima diversidad 4.49 bits/cél. en verano y 2.57 bits/cél. en invierno. La equidad durante el verano registró valores que nos indica una mayor homogeneidad en la distribución de las especies, mientras que en las demás estaciones del año el comportamiento fue heterogéneo. En primavera de 1999 en Paso del Durazno se registró $E=$ 0.45 mientras que en el otoño $E=0.95$ (Fig. 6).

Tabla 5. Valores del Índice diatómico de Sladecek (1984, 1986) aplicado en cada sitio de muestreo y estación del año. Sladecek Diatomic Index (1984-1986) values applied to each sampling site and season.

\begin{tabular}{|l|c|cc|c|c|}
\hline & \multicolumn{5}{|c|}{ Primavera de 1999 } \\
\hline & TA & EM & PA & SC & PD \\
\hline IDS: & 2.37 & 2.53 & 2.81 & 2.69 & 4 \\
\hline \multicolumn{5}{|c|}{ Verano de 2000 } \\
\hline IDS: & 2.34 & 2.14 & 2.88 & 3 \\
\hline \multicolumn{5}{|c|}{ Otoño de 2000 } \\
\hline IDS: & 2.47 & 2.39 & 2.87 \\
\hline \multicolumn{5}{|c|}{ Invierno de 2000 } \\
\hline IDS: & 2.54 & 2.58 & 2.23 \\
\hline \multicolumn{5}{|c|}{2.26} \\
\hline IDS: & 2.46 & 2.42 & 2.36 \\
\hline
\end{tabular}



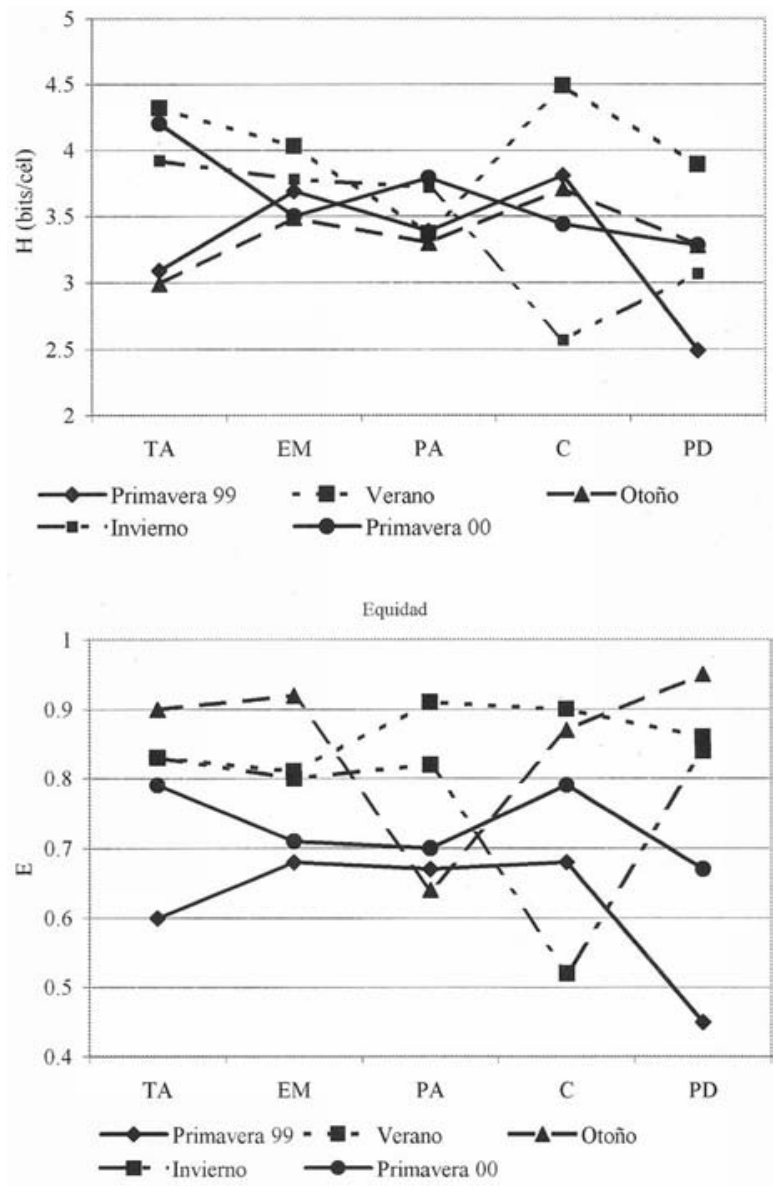

Figura 6. Variación estacional de los índices de Diversidad (Shannon Weaver) y Equidad de la comunidad fitoplanctónica. Seasonal variation of the (Shannon Weaver) Diversity Index and Equity Index of the phytoplankton community.

El recuento de bacterias coliformes totales fue más elevado en el sitio Paso del Durazno con $7 \cdot 10^{5}$ y $9 \cdot 10^{5} \mathrm{NMP} / \mathrm{ml}$ durante la estación de otoño y verano respectivamente. La carga de bacterias aerobias mesófilas viables prevaleció en primavera de 2000 en todas las estaciones de muestreo, registrando un valor máximo de $1.5 \cdot 10^{6}$ UFC/ml en Paso del Durazno (Figs. 7 y 8).

La aplicación del índice de Sladecek para determinar calidad de agua expresa valores dentro del rango $\beta$-mesosaprobios, contaminación moderada a alta, para los sitios Tres Acequias, El Mogote y Puente Antártica Argentina y polisaprobios, contaminación alta, en el sector Cloacas y Paso del Durazno (Tabla 5).

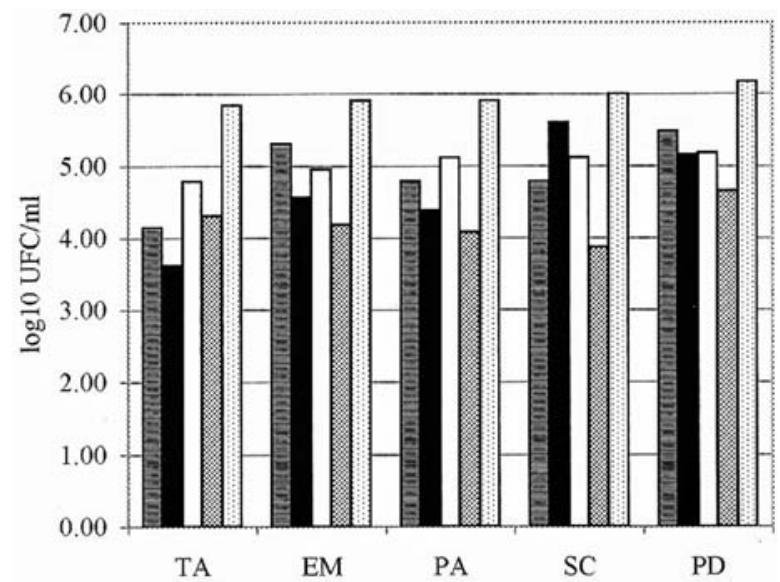

曰Primavera 99 Verano $\square$ Otoño 0 Invierno EPrimavera 00

Figura 7. Recuento de bacterias coliformes totales en el río Cuarto. Coliform bacteria total counting for the Cuarto River.

\section{DISCUSIÓN Y CONCLUSIONES}

Las características geoquímicas del agua, en los sitios de muestreo estudiados, pertenecen al mismo tipo sin diferencias importantes que manifiesten condiciones especiales en alguna de ellas.

Los valores de $\mathrm{pH}$, ligeramente alcalinos, son levemente mayores a los señalados para este sector del río por Corigliano et al., (1994).

Los nitratos resultantes de la oxidación de compuestos nitrogenados superaron ligeramente la mínima concentración que indica la presencia de detritos orgánicos provenientes de la acción antrópica, lo que demuestra que las aguas del río Cuarto tienen gran capacidad de oxidación, favorecida por la velocidad de corriente, poca profundidad del curso fluvial y niveles de oxígeno disuelto dentro de los rangos de saturación (Martínez de Fabricius, 1996).

Las diatomeas del orden Pennales predominaron en este tramo del río Cuarto, hecho coincidente con investigaciones realizadas por Martínez de Fabricius (1996) que pone en evidencia que el déficit de diatomeas céntricas ocurre tanto en zonas de cabecera como río abajo, contrariamente a los resultados obtenidos para ríos de mayor envergadura (O'Farrell, 1993). Si bien no existe una clasificación regional de los 


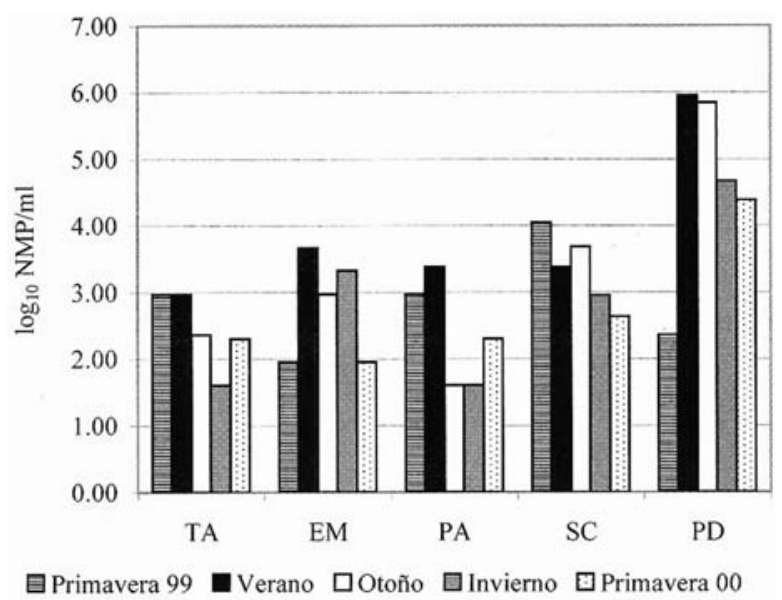

Figura 8. Recuento de bacterias aeróbias mesófilas viables totales en el río Cuarto. Total viable aerobic mesophyle bacteria for the Cuarto River.

ríos en base a las algas en suspensión y en transporte, los ríos de corriente rápida se caracterizarían por el predominio de diatomeas pennadas, derivadas del perifiton y el bentos, entre otras comunidades (Seeligman et al., 2001). En Luque \& Martínez de Fabricius (2000) se menciona el aporte más o menos continuo del epiliton a la fracción planctónica, como consecuencia de las características morfológicas e hidrológicas del río Piedra Blanca, principal afluente del río Cuarto, similar comportamiento se puede esperar en el río Cuarto, más aún si se considera que es un río de substrato arenoso, de poca profundidad y de régimen torrencial.

Nitzschia palea fue la especie más abundante, según Bruno et al., (2003) es frecuente en aguas polucionadas o con influencia antrópica. Sin embargo en el sitio Cloacas, con efluvios cloacales, esta especie no evidenció elevada densidad. Probablemente la descarga orgánica es significativa en el lugar pero por el tipo de sustrato que presenta el río Cuarto (grava y arena) y variación del flujo del agua, la materia orgánica es rápidamente oxidada no afectando la comunidad algal (Martínez de Fabricius et al., 2003). De acuerdo a Rojo et al (1994), las diatomeas parecen ser un grupo taxonómico que responde más rápidamente a los cambios ambientales en cursos fluviales inestables, sin embargo durante el invierno el impacto de este efluente es ma- yor debido a la época de estiaje. Esta situación hidrológica de menor caudal trae aparejado una menor dilución y como consecuencia una mayor concentración de materia orgánica. En este período, la densidad algal fue la más elevada, la diversidad fue menor, destacándose las especies Melosira varians y Diatoma vulgare. Estas taxa, que forman cadenas, son frecuentes en el sedimento en períodos de bajo flujo (Martínez de Fabricius et. al., 2003). Considerando el aporte continuo del epiliton y epipsamon a la fracción planctónica, como consecuencia de las características hidrológicas del río (Luque \& Martínez de Fabricius, 2003), se explica la abundancia algal en el potamoplancton. Si bien las diatomeas prevalecieron durante el año, la composición taxonómica del río fue cambiando estacionalmente. Así en primavera predominaron Nitzschia linearis, N. palea y Synedra ulna; en verano Navicula rhyncocephala; en otoño Navicula perminuta y en invierno Melosira varians y Nitzschia linearis. La comunidad algal está dominada por especies de Navicula y Nitzschia, favorecida por las condiciones del agua mineralizadas (Lange-Bertalot, 1980) y sustrato arenoso que alberga diatomeas epipsámicas de estos géneros. Para este sector del río, en relación a las diatomeas bénticas, el desarrollo de formas pedunculares como especies de Gomphomema y Cymbella han sido descriptas como características de aguas alcalinas y curso de corriente moderada, en coincidencia con las investigaciones de Martínez de Fabricius et al., (2003). Las Chlorophyta y Cyanophyta fueron menos abundantes, prevaleciendo en otoño en el sitio urbano. La predominancia de Anabaena sp., en otoño, es coincidente con los estudios efectuados por Bruno et al., (2003) para este sector del río.

Según Basu \& Pick (1995) manifiesta que la biomasa del fitoplancton en ríos está fuertemente correlacionada con las concentraciones de nutrientes, no así con el tiempo de residencia del agua. Esto concuerda con los resultados obtenidos donde la diversidad se ajustó mejor a los cambios que tuvieron lugar en relación a la carga orgánica.

Los resultados bacteriológicos indican una moderada carga de microorganismos totales a lo largo del curso del río, destacándose el 
efecto del vuelco de los efluentes cloacales, evidenciado también por la presencia de especies algales de mayor valor sapróbico. Los valores de saprobiedad y el índice biótico reflejaron las diferencias locales debidas a las distintas actividades humanas desarrolladas en cada tramo a lo largo de la cuenca.

\section{BIBLIOGRAFÍA}

APHA. 1989. Standard Methods for the examination of water and wastewater. $18^{\text {th }}$. Ed. American Public Health Association, Washington, DC. 874 pp.

ARCHIBALD, R. E. M. 1983. The Diatoms of the Sundays and Great at Fish River in the Eastern Cape Province of South Africa. Bibl. Diatomologica, 1: 1-362, 34 láms. J. Cramer, Vaduz.

BASU, B. K. \& F. R. PICK. 1995. Longitudinal and seasonal development of planktonic chlorophyll a in the Rideau River, Ontario. Can. J. Fish. Aquat. Sci., 52: 804-815.

BATTARBEE, E. W. 1986. Diatom Analysis. In: Handbook of Holocene Palaeoecology and Palaeohydrology. B. E. Berglund (ed.): 527-570. J. Wiley \& Sons, New York.

BOURRELLY, P. 1981. Les Algues d'eau douce. Les algues jaunes et brune. II. Ed. Boubée, París. 517 pp. 118 láms.

BOURRELLY, P. 1985. Les Algues d'eau douce. Les algues bleues et rouges. III. Ed. Boubée, París. 606 pp. 139 láms.

BOURRELLY, P. 1990. Les Algues d'eau douce. Les algues vertes. I. Ed. Boubée, París. 172 pp. 121 láms.

BRUNO, E., A. L. MARTINEZ de FABRICIUS Y M. E. LUQUE. 2003. Fitoplancton en un tramo del río Cuarto con influencia antrópica. Bol. Soc. Argent. Bot., 38(3-4): 241-254.

CANTU, M. \& S. DEGIOVANNI. 1984. Geomorfología de la región centro-sur de la provincia de Córdoba. Actas IX Congreso Geología Argentino. S. C. Bariloche: 76-92.

CORIGLIANO, M. del C., A. L. MARTINEZ de FABRICIUS, M. E. LUQUE Y N. GARI. 1994. Patrones de distribución de variables fisicoquímicas y biológicas en el río Chocancharava (Cuarto) (Córdoba, Argentina). Revista UNRC, 14: 177-194.

DESIKACHARY, T. V. 1959. Cyanophyta. Ed. Board, New Delhi. 545 pp.
GERMAIN, H. 1981. Flore des Diatomeés. Ed. Boubée, Paris. 448 pp.

KRAMMER, K. \& H. LANGE-BERTALOT. 1986. Bacillariophyceae 2. Naviculaceae. 2/1. G. F. Verlag, Jena. 875 pp.

KRAMMER, K. \& H. LANGE-BERTALOT. 1988. Bacillariophyceae 2. Bacillariaceae, Ephitemiaceae, Surirellaceae 2/2. G. Fischer, Stuttgart. 596 pp.

KRAMMER, K. \& H. LANGE-BERTALOT. 1991a. Bacillariophyceae 3. Centrales, Fragilariaceae, Eunotiaceae. 2/3. G. Fischer, Stuttgart. New York. 576 pp.

KRAMMER, K. \& H. LANGE-BERTALOT. 1991b. Bacillariophyceae 4. Achnanthaceae. 2/4. G. Fischer, Stuttgart. New York. 437 pp.

LANGE-BERTALOT, H. 1980. Fur taxonomischen Revisión ökologischer wichtiger Navicula lineolatae Cleve. Die Formenkreise um Navicula lanceolata, Navicula viridula und Navicula cari. Cryptogamie Algologie 1: 29-50.

LUQUE, M. E., N. GARI Y A. L. MARTINEZ de FABRICIUS. 1997. Fitoplancton y fitobentos de la cuenca superior del río Chocancharava (ex Cuarto) (Córdoba, Argentina). Revista UNRC, 17: 49-67.

LUQUE, M. E. \& A. L. MARTINEZ DE FABRICIUS. 2000. Ficoflora fitoplanctónica y epilítica del río Piedra Blanca (Córdoba, Argentina). Bol. Soc. Argent. Bot., 35 (1-2): 21-32.

LUQUE, M. E. \& A. L. MARTINEZ DE FABRICIUS. 2002. Distribución temporal de algas epilíticas en el río Piedra Blanca (Córdoba, Argentina). Bol. Soc. Argent. Bot., 37 (1-2): 29-39.

LUQUE, M. E. \& A. L. MARTINEZ DE FABRICIUS. 2003. Distribución temporal del fitoplancton y epiliton en el río Piedra Blanca (Córdoba, Argentina). Limnetica, 22 (3-4): 19-34

MARTINEZ de FABRICIUS, A. L., M. C. FERNÁNDEZ BELMONTE, E. N. GARI Y M. del C. CORIGLIANO. 1988. Análisis del componente algal en transporte en ríos y arroyos del Valle de Calamuchita (Córdoba, Argentina). Revista UNRC, 8: 95-110.

MARTINEZ de FABRICIUS, A. L. Y M. del C. CORIGLIANO. 1989. Composición y distribución de comunidades algales en el río Ctalamochita (Córdoba, Argentina). Revista UNRC, 9: 5-13.

MARTINEZ de FABRICIUS, A. L. 1996. Bacillariophyceae del río Cuarto. Provincia de Córdoba, Argentina. Tesis Doctoral No 673. Universidad Nacional de la La Plata. 289 pp. 17 láms. 
MARTINEZ de FABRICIUS, A. L., N. MAIDANA, N. GOMEZ \& S. SABATER. 2003. Distribution patterns of benthic diatoms in a Pampean river exposed to seasonal flods: the Cuarto river (Argentina). Biodiversity and Conservation, 12: 2443-2454.

MIRANDE, V., N. ROMERO; M. A. BARRIONUEVO; G. S. MEONI; B. NAVARRO; M. C. APELLA \& B. C. TRACANNA. 1999. Human impact on some limnological characteristics of the Gastona river (Tucumán, Argentina). Acta Limnológica Brasiliensia, 11(2): 101-110.

O'FARRELL, I. 1993. Phytoplankton ecology and limnology of the Salado River (Buenos Aires, Argentina). Hydrobiologia, 271: 169-178.

PATRICK, R. \& C. W. REIMER. 1966. The Diatoms of the United States exclusive of Alaska and Hawai. Vol. 1 Acad. Nat. Sci. Philadelphia. Monog., 13: 1-688.

PATRICK, R. \& C. W. REIMER. 1975. The Diatoms of the United States exclusive of Alaska and Hawai. Vol. 2 Acad. Nat. Sci. Philadelphia. Monog., 13: 1-213.

PEREZ, M. del C. 2002. Fitoplancton del río Negro, Uruguay. Limnetica, 21 (1-2): 81-92.

PRESCOTT, G. W. 1962. Algae of the Western Great lake area. N. M C. Brow. Co. Ine. 977 pp.

ROJO, C., M. ALVAREZ COBELAS \& M. ARAUZO. 1994. An elementary, structural análisis of river phytoplankton. Hydrobiologia, 289: 43-55.

ROUND, F. E. \& BUKHTIYAROVA, L. 1996. Four new genera based on Achnanthes (Achnanthidium) together with a re-definition of Achnanthidium. Diatom Research, 11 (2): 345-361.

SEILER, R. A., R. A. FABRICIUS, V. ROTONDO Y M. VINOCUR. 1995. Agroclimatología de Río Cuarto (1974-1993) Vol. 1. Fac. Agronomía y Veterinaria-UNRC. 68 pp.
SEELIGMAN, C., B. C. TRACANNA, S. MARTÍNEZ DE MARCO Y S. ISASMENDI. 2001. Algas fitoplanctónicas en la evaluación de la calidad del agua de sistemas lóticos en el noroeste Argentino. Limnetica, 20 (1): 123-133.

SHANNON, C. E. \& W. WEAVER. 1963. The mathematical theory of communication. Univ. Illinois Press, Urbana. 117 pp.

SLADECEK, V. 1984. Diatoms as indicators of organic pollution. In: 8th Intern. Diatom Symposium, París, Aug. 1984. M. Ricard (ed.): 757-758. Koeltz Koenigstein Publ.

SLADECEK, V. 1986. Diatoms as indiators of organic pollution. Acta Hydrochim. Hydrobiologia, 14 (5): 555-566,

STOERMER, E. F., R. G. KREIS \& N. A. ANDERSEN. 1999. Checklist of Diatoms from the Laurentian Great Lakes: II. J. Great lakes Res., 25 (3): 545-566.

TORO, M., S. ROBLES, J. AVILÉS, C. NUÑO, S. VIVAS, N. BONADA, N. PRAT, J. ALBATERCEDOR, J. CASAS, C. GUERRERO, P. JÁIMEZ-CUÉLLAR, J. L. MORENO, G. MOYÁ, G. RAMON, M. L. SUÁREZ, M. R. VIDALABARCA, M. ALVAREZ \& I. PARDO. 2002. Calidad de las aguas de los ríos mediterráneos del proyecto GUADALMED. Características físicoquímicas. Limnetica, 21 (3-4): 63-75.

TRACANNA, B., C. T. SEELIGMANN, V. MIRANDE, L. B. De PARRA, M. T. De PLAZA Y F. Molinari. 1999. Cambios espaciales y temporales del fitoplancton en el embalse Río Hondo (Argentina). Bol. Soc. Argent. Bot., 34 (1-2): 101-105.

VILLAFAÑE, V. E. \& F. M. H. REID. 1995. Métodos de microscopia para la cuantificación del fitoplancton. En: Manual de Métodos Ficológicos, K. Alveal, M. E. Ferrario, E. C. Oliveira \& E. Sar (eds): 169-185. Edit. Universitaria, Concepción. 